\title{
Effect of flow perfusion on the osteogenic differentiation of bone marrow stromal cells cultured on starch-based three-dimensional scaffolds
}

\author{
Manuela E. Gomes, ${ }^{1,2,3}$ Vassilios I. Sikavitsas, ${ }^{4}$ Esfandiar Behravesh ${ }^{3}$ Rui L. Reis, ${ }^{1,2}$ Antonios G. Mikos ${ }^{3}$ \\ ${ }^{1}$ Department of Polymer Engineering, University of Minho, 4800-058 Guimarães, Portugal \\ ${ }^{2} 3$ Bs Research Group, Biomaterials, Biodegradables, and Biomimetics, University of Minho, 4710-057 Braga, Portugal \\ ${ }^{3}$ Department of Bioengineering, Rice University, 6100 Main Street, Houston, Texas 77251-1892 \\ ${ }^{4}$ School of Chemical Engineering and Materials Science, University of Oklahoma, 100 E. Boyd, \\ Norman, Oklahoma 73019
}

Received 31 January 2003; accepted 5 February 2003

\begin{abstract}
This study aims to investigate the effect of culturing conditions (static and flow perfusion) on the proliferation and osteogenic differentiation of rat bone marrow stromal cells seeded on two novel scaffolds exhibiting distinct porous structures. Specifically, scaffolds based on SEVA-C (a blend of starch with ethylene vinyl alcohol) and SPCL (a blend of starch with polycaprolactone) were examined in static and flow perfusion culture. SEVA-C scaffolds were formed using an extrusion process, whereas SPCL scaffolds were obtained by a fiber bonding process. For this purpose, these scaffolds were seeded with marrow stromal cells harvested from femoras and tibias of Wistar rats and cultured in a flow perfusion bioreactor and in 6-well plates for 3,7 , and 15 days. The proliferation and alkaline phosphatase activity patterns were similar for both types of scaffolds and for both culture conditions. However, calcium content analysis revealed a significant enhancement of calcium deposition on both scaffold types cultured under flow
\end{abstract}

perfusion. This observation was confirmed by Von Kossastained sections and tetracycline fluorescence. Histological analysis and confocal images of the cultured scaffolds showed a much better distribution of cells within the SPCL scaffolds than the SEVA-C scaffolds, which had limited pore interconnectivity, under flow perfusion conditions. In the scaffolds cultured under static conditions, only a surface layer of cells was observed. These results suggest that flow perfusion culture enhances the osteogenic differentiation of marrow stromal cells and improves their distribution in three-dimensional, starch-based scaffolds. They also indicate that scaffold architecture and especially pore interconnectivity affect the homogeneity of the formed tissue. (C) 2003 Wiley Periodicals, Inc. J Biomed Mater Res 67A: 87-95, 2003

Key words: bone tissue engineering; bone marrow stromal cells; flow perfusion bioreactor; biodegradable polymers; starch-based scaffolds

\section{INTRODUCTION}

One of the most widely studied tissue engineering approaches involves the seeding and extended in vitro culturing of cells within a biodegradable scaffold before implantation. The bioresorbable scaffold must be biocompatible and porous to facilitate rapid vascularization and growth of newly formed tissue. ${ }^{1-8}$ During the in vitro culture period, the seeded cells proliferate and secrete tissue specific extracellular matrix (ECM).

Correspondence to: A.G. Mikos; e-mail: mikos@rice.edu

Contract grant sponsor: National Institutes of Health; contract grant number: R01-AR42639 (to A.G.M.)

Contract grant sponsor: Portuguese Foundation for Science and Technology; contract grant number: SFRH/BD/ 4704/2001 (to M.G.)

(c) 2003 Wiley Periodicals, Inc.
After implantation, the scaffold gradually degrades and is eventually eliminated from the body. ${ }^{1-8}$

The selection of an appropriate scaffold material is a primary consideration in such a tissue engineering strategy. ${ }^{9}$ Besides the obvious demands of biocompatibility and biodegradability, an ideal tissue engineering scaffold should have appropriate mechanical properties $^{1,10-14}$ and a suitable degradation rate. ${ }^{2,10,12-15}$ Furthermore, the scaffold must possess adequate porosity, interconnectivity, and permeability to allow the ingress of cells and nutrients ${ }^{12-15}$ as well as the appropriate surface chemistry for enhanced cell attachment and proliferation. 3,12,13,16 Several biodegradable polymers have been proposed to be used as three-dimensional scaffolds for bone tissue engineering, including a new range of natural origin polymers based on starch. ${ }^{17}$ Starch-based polymers are degradable and biocompatible polymers, ${ }^{18-20}$ with distinct structural forms and properties 
that can be tailored by the synthetic component of the starch-based blend, their processing methods, and the incorporation of additives and reinforcement materials. For this reason, together with their low cost and abundance of raw materials, starch-based polymers have been suggested for a wide range of biomedical applications.

Another important consideration for tissue engineering approaches based on in vitro cell culture is the cell source and the ability to control cell proliferation and differentiation. Marrow stromal cells constitute a potential autogenous source of cells for bone tissue engineering because they can be expanded, differentiated into osteoblasts, and used to seed the scaffolds. ${ }^{21}$

Besides the selection of the scaffold material and the cell source, several other issues should be considered, including the optimization of the in vitro culturing system. Static culturing conditions often result in inhomogeneous cell distribution, confining the majority of the cells to the outer surfaces of the scaffold. Accordingly, an inhomogeneous distribution of the extracellular matrix commonly results. ${ }^{22-24}$ In order to overcome this limitation, several bioreactors have been developed, ${ }^{22-28}$ attempting to maintain a uniform distribution of cells on the scaffolds, to provide adequate levels of oxygen, nutrients, cytokines, and growth factors, and to expose the cultured cells to mechanical stimuli. Most bioreactors used in bone tissue engineering applications achieve good mixing of the culturing media near the construct outer surface, but not to its interior. This inability represents a major drawback, particularly in the culturing of scaffolds for the reconstruction of large bone defects. Our laboratory has developed a flow perfusion bioreactor, which provides uniform flow to the interior and exterior of the cultured scaffolds. ${ }^{26}$

In this study we have investigated the influence of the cell culturing conditions generated by this flow perfusion bioreactor on the proliferation and osteogenic differentiation of rat bone marrow stromal cells seeded into two types of starch-based scaffolds. This study addresses the following questions: (i) Are starch based scaffolds able to support adhesion and proliferation of rat bone marrow cells? (ii) Does flow perfusion allow for enhanced osteogenic differentiation and homogenous spatial distribution of the seeded cells? (iii) Does the different porosity and pore architecture of these scaffolds influence the proliferation, differentiation, and distribution of cells under flow perfusion culture conditions?

\section{MATERIALS AND METHODS}

\section{Scaffold preparation and characterization}

Two different types of starch-based polymer scaffolds were used in this study: (i) a scaffold based on SEVA-C (a
$50 / 50 \%$ wt blend of starch with ethylene vinyl alcohol) obtained by extrusion with a blowing agent and (ii) a scaffold based on SPCL (a blend of starch with polycaprolactone, $30 / 70 \% \mathrm{wt}$ ) obtained by a fiber bonding process. Further information on starch-based polymer scaffolds and their processing can be found elsewhere. ${ }^{17}$ The morphology of the scaffolds was characterized by microcomputerized tomography $(\mu \mathrm{CT}$; ScanCo Medical $\mu \mathrm{CT}$ 80, Bassersdorf, Switzerland) at a resolution of $10 \mu \mathrm{m}$. All samples were cut into discs of approximately $8 \mathrm{~mm}$ diameter and $1.5-2 \mathrm{~mm}$ height and sterilized using ethylene oxide. Before cell seeding, the scaffolds were immersed in $30 \mathrm{~mL}$ of serum-free media in 50-mL tubes. Air was removed from their pores by generating vacuum with a 30-mL syringe equipped with an 18-gauge needle. The scaffolds were left in serum-free media overnight to allow swelling.

\section{Isolation and expansion of rat bone marrow cells}

Rat bone marrow stromal cells were isolated and cultured using methods previously described. ${ }^{29}$ Briefly, cells were obtained from the femoras and tibias of male Wistar rats with weights ranging from 125 to $149 \mathrm{~g}$ (Harlan). The epiphyses were cut off, and the diaphyses flushed with $5 \mathrm{~mL}$ of complete media [ $\alpha$-MEM (minimal essential medium); Eagle, Sigma, St. Louis, MO], supplemented with $10 \%$ FCS (fetal calf serum; Gemini), $50 \mu \mathrm{g} / \mathrm{mL}$ ascorbic acid (Sigma), $50 \mu \mathrm{g} / \mathrm{mL}$ gentamycin, $100 \mu \mathrm{g} / \mathrm{mL}$ ampicillin, $0.3 \mu \mathrm{g} / \mathrm{mL}$ fungizone, $10 \mathrm{mM} \beta$-glycerophosphate (Sigma), and $10^{-8} \mathrm{M}$ dexamethasone (Sigma). Cells were cultured in complete media in a humidified atmosphere of $5 \% \mathrm{CO}_{2}$ at $37^{\circ} \mathrm{C}$ for 6 days.

\section{Cell seeding on starch-based scaffolds}

After 6 days of primary culture, the cells were detached using trypsin/EDTA $(0.25 \% \mathrm{w} / \mathrm{v}$ trypsin/0.02\% EDTA, Sigma), concentrated by centrifugation at $1500 \mathrm{rpm}$ for $5 \mathrm{~min}$ and resuspended in complete media. Subsequently, the scaffolds ( $n=18$ for flow and $n=18$ for static culture, for each scaffold type) were inserted into cassettes that were placed in six-well plates. Each scaffold was then seeded with $300 \mu \mathrm{l}$ of a cells suspension containing $5 \times 10^{5}$ cells and incubated for $2 \mathrm{~h}$. Then $10 \mathrm{~mL}$ of complete media was added to each well. The seeded scaffolds were further incubated overnight to allow for cell attachment. The following day, seeded scaffolds were placed into fresh six-well plates for static culture conditions or into the flow perfusion bioreactor and cultured in complete media for 3, 7, and 15 days (6 scaffolds per culture condition and per culture time).

\section{Cell culturing: the flow perfusion culture system}

The flow perfusion bioreactor is described in detail elsewhere. ${ }^{26}$ Briefly, the bioreactor consists of six flow chambers, 
each one containing a cassette in which the scaffold is pressfitted. Gas-permeable silicon tubing connects each flow chamber with a peristaltic pump and a medium reservoir. Each chamber has its own independent pumping circuit, but all pumps draw media from a common reservoir. For these experiments, culture media was pumped continuously at a flow rate of $0.3 \mathrm{~mL} / \mathrm{min}$ through the cell/scaffold construct cassette/housing unit and recirculated back to the reservoir. The total volume of medium in the flow system was $210 \mathrm{~mL}$. In the static culture, $10 \mathrm{~mL}$ was added to each scaffold. In both culture systems, media were changed every 3 days.

The entire flow perfusion bioreactor was maintained in an environment of $37^{\circ} \mathrm{C}$ with $5 \% \mathrm{CO}_{2}$. At the end of each culturing period, the cell/scaffold constructs were rinsed with phosphate buffered saline (PBS) and stored at $-70^{\circ} \mathrm{C}$ in 10 -mL tubes containing $1.4 \mathrm{~mL}$ of milliQ water for DNA, calcium, and alkaline phosphatase (ALP) analysis. At each time point, two scaffolds from each group were retrieved: one was fixed in a solution of $2.5 \%$ gluteraldehyde for SEM analysis and the other in a formalin solution for histological evaluation.

\section{Characterization of the cultured scaffolds}

Cellularity of scaffolds

The DNA content of each scaffold was measured using a PicoGreen DNA Quantification Kit (Molecular Probes). The samples were allowed to thaw at room temperature and then were sonicated for roughly $15 \mathrm{~min}$. A description of the assay can be found elsewhere. ${ }^{29}$ The cellularity of each scaffold was then calculated by correlation with the DNA of a known amount of marrow stromal cells.

\section{ALP activity}

ALP activity was measured using a Sigma Diagnostic Kit (no. 104), a colorimetric endpoint assay that measures the conversion of $p$-nitrophenol phosphate to $p$-nitrophenol by the enzyme ALP. ${ }^{26}$

\section{Calcium content of scaffolds}

Cell/scaffold constructs were incubated overnight in $1 \mathrm{~N}$ acetic acid to dissolve the deposited calcium. The calcium content was then measured using the Sigma Diagnostic Kit (no. 587). This colorimetric endpoint assay measures the amount of calcium-cresolphthalein complexone formed when cresolphthalein complexone binds to free calcium in an alkaline solution. The amount of deposited calcium was expressed as mg of $\mathrm{Ca}^{2+}$ equivalents per scaffold. ${ }^{26}$

\section{Scanning electron microscopy}

For scanning electron microscopy (SEM) analysis the samples were fixed in a solution of $2.5 \%$ glutaraldehyde (in PBS), dehydrated in a gradient series of ethanol solutions, dried with tetramethylsilane, and sputter-coated with gold (Jeol JFC 1100, Jeol). Samples were then observed using a scanning electron microscope (Leica Cambridge S360, Leica Cambridge, UK).

\section{Confocal microscopy}

To visualize the distribution of cells within the scaffolds, samples cultured for 15 days (previously fixed with glutaraldehyde) were cut in half (to expose the interior cross section), rinsed with PBS, incubated with picogreen dye $(0.1 \%)$ for at least $15 \mathrm{~min}$, and then observed under a confocal microscope (Zeiss LSM Axiovert, Carl Zeiss, Oberkochen, Germany). Depth projections of the surface (up to $300 \mu \mathrm{m}$ ) were obtained and the cells were pseudo-colored as a function of their distance from the surface.

Histology and imaging of tetracycline fluorescence

The cultured samples were rinsed with PBS, fixed in formalin, rinsed with water, and embedded in frozen tissue embedding media (HistoPrep, Fisher Diagnostic). Sections of $\sim 30 \mu \mathrm{m}$ were obtained using a cryotome (Microm 505) and stained with hematoxylin and eosin for histological evaluation. For visualization of mineralized tissue, additional sections were exposed to a $5 \%$ silver nitrate solution under UV light for $25 \mathrm{~min}$ and counterstained with a safranin $\mathrm{O}$ solution $(0.5 \%)$. Mineral deposition was also observed in unstained sections under fluorescent light after adding tetracycline- $\mathrm{HCl}(10 \mu \mathrm{g} / \mathrm{mL})$ to the culture media as described previously. ${ }^{23}$ All the histological sections were observed with a light microscope (Nikon E600) equipped with a Sony DXC-950P CCD camera and a fluorescence lamp.

\section{Statistics}

Results are presented as means \pm standard deviation. Multiple pairwise comparisons were performed using the Tukey-Kramer method with a significance level of $95 \%$.

\section{RESULTS AND DISCUSSION}

\section{Characterization of the scaffolds}

The SPCL scaffold has a typical fiber-mesh structure, with a fiber diameter roughly $181 \mu \mathrm{m}$, with highly interconnected pores and a porosity of $\sim 75 \%$, as determined by $\mu \mathrm{CT}$ analysis [Fig. 1(a)]. The SEVA-C based scaffolds were obtained by extrusion with a blowing agent creating pores within the polymer melt as the blowing agent releases $\mathrm{CO}_{2}$. The pores are not completely interconnected, as shown on the $\mu \mathrm{CT}$ scan of this scaffold [Fig. 1(b)]. The porosity of 

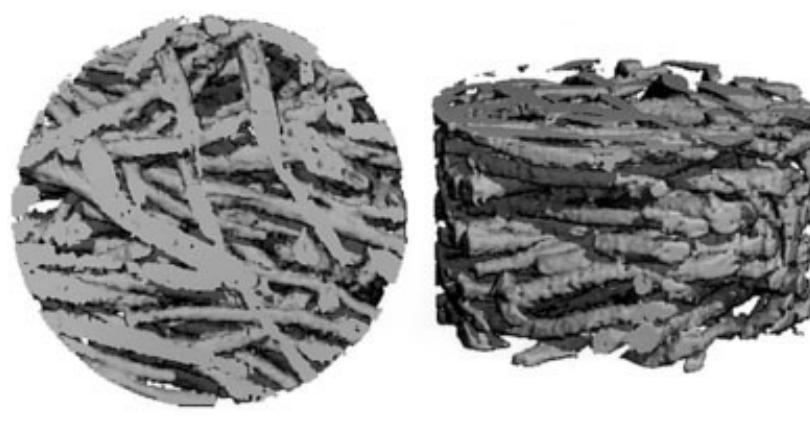

a)
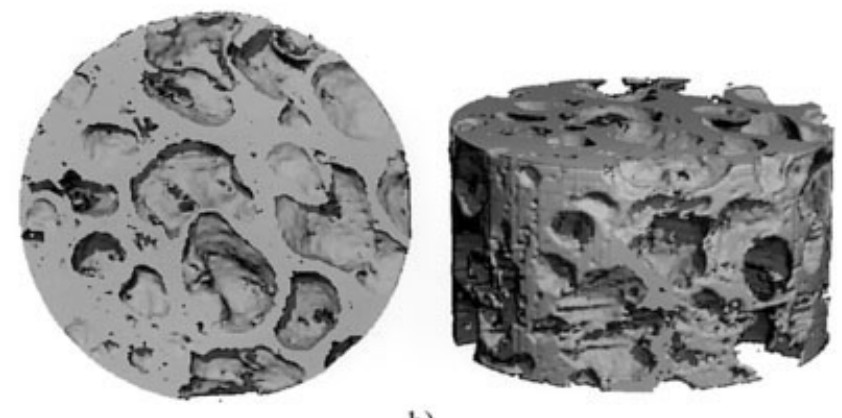

b)

Figure 1. Representative $\mu \mathrm{CT}$ scans of (a) SPCL based scaffold (top and side view) and (b) SEVA-C based scaffold (top and side view).

these scaffold was approximately $60 \%$ as determined by $\mu \mathrm{CT}$ analysis.

\section{DNA analysis}

Figure 2(a,b) depicts the number of cells present in each scaffold at each time point, calculated from DNA measurements. In both static and flow perfusion cultures, cell proliferation occurred during the first week of culture. These results agree with the initial period of osteoblastic development characterized by active cellular proliferation. ${ }^{31}$ Similar cellular growth patterns were observed for both static and flow cultures. Flow perfusion appears to enhance cell proliferation when compared with static culture. This trend was found to be significant $(p<0.05)$ for SEVA-C scaffolds cultured for 15 days under flow perfusion. However, when cell proliferation between the two scaffolds cultured in flow perfusion is compared, enhanced proliferation is observed on the SPCL fiber meshes. This may be related to the different synthetic components of the starch-based blend or to the higher porosity and interconnectivity of the SPCL scaffolds.

During the second week of culture, the cellularity of all scaffolds did not increase further. This period cor- responds to the stages of matrix maturation, late osteoblastic differentiation, and mineralization. Similar cell proliferation patterns, characterized by an increase in cell number during the first period of culture followed by a period where the cell number remained constant or even decreased, have been observed in earlier studies with marrow stromal cells seeded into titanium fiber mesh scaffolds and cultured under flow perfusion and static conditions. ${ }^{23,26}$

\section{ALP analysis}

The ALP activity of marrow stromal cells has been shown to indicate the commitment of these cells to-

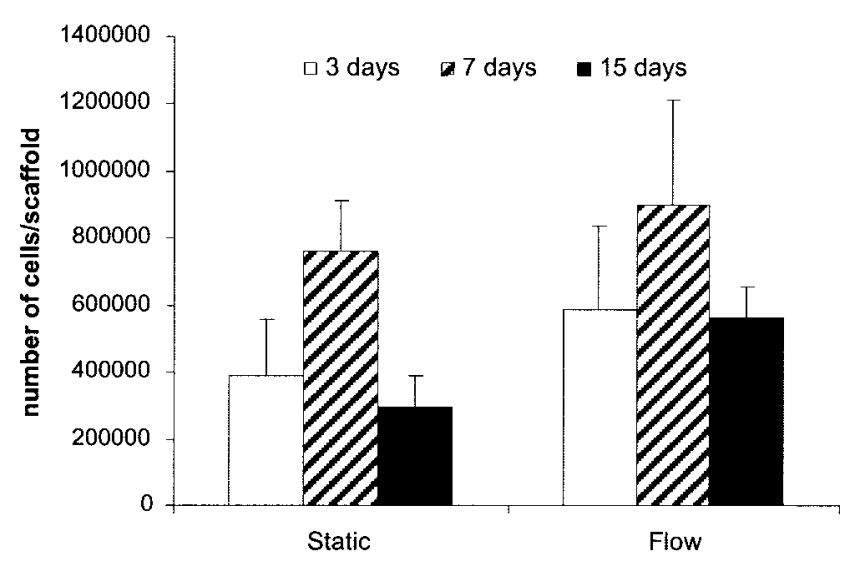

a)

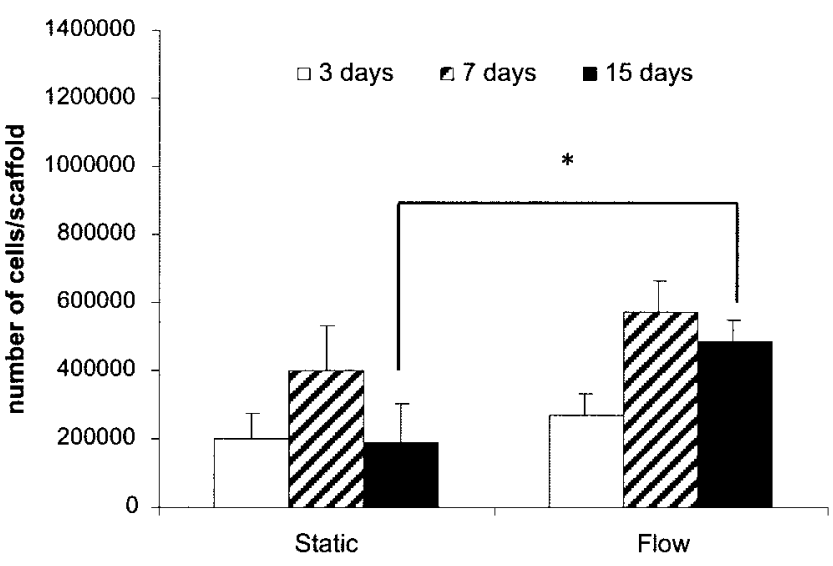

b)

Figure 2. Number of cells on (a) SPCL fiber meshes and (b) SEVA-C based scaffolds after 3, 7, and 15 days of culture under static and flow perfusion conditions. Error bars, means \pm standard deviation for $n=3-5$. Asterisk $(*)$ indicates that the cellularity of SEVA-C scaffolds cultured under flow perfusion conditions after 15 days of culture was significantly higher $(p<0.05)$ than the cellularity of scaffolds cultured under static conditions for 15 days. 


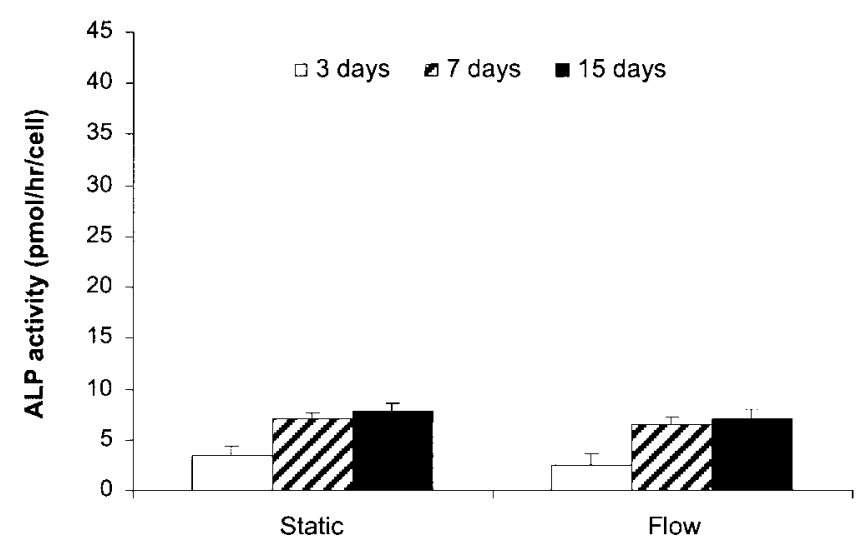

a)

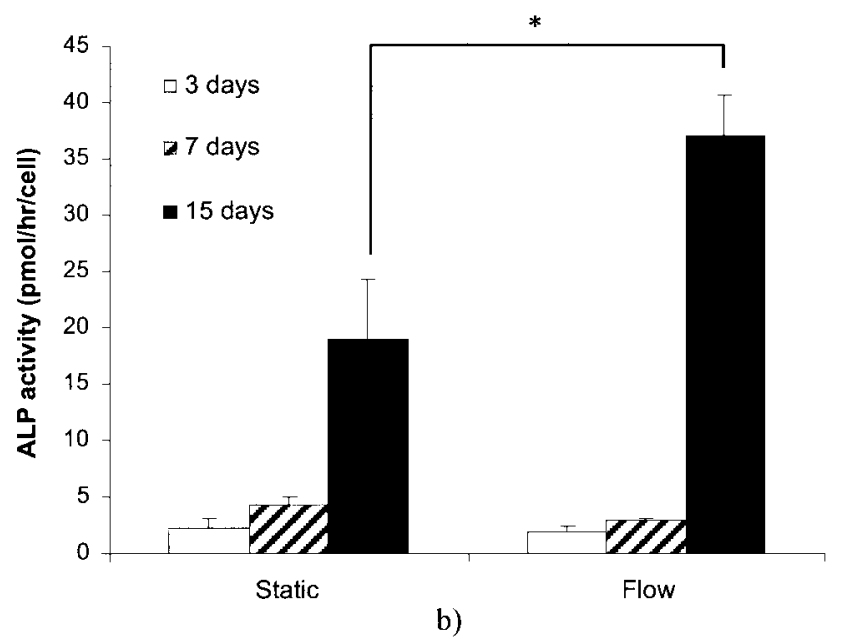

Figure 3. Normalized ALP activity of marrow stromal cells after 3, 7, and 15 days of culture on (a) SPCL fiber meshes and (b) SEVA-C based scaffolds under static and flow perfusion conditions. Error bars, means \pm standard deviation for $n=3-5$. Asterisk $\left({ }^{*}\right)$ indicates that the ALP activity of SEVA-C scaffolds cultured under flow perfusion conditions after 15 days of culture was significantly higher $(p<0.05)$ than the ALP activity of scaffolds cultured under static conditions for 15 days.

ward the osteoblastic lineage $\mathrm{e}^{31}$ and usually reaches a maximum that coincides with the early osteoblastic differentiation stage of marrow stromal cells. After this period, the ALP activity usually decreases and mineralization starts to take place. In this study, a continuous increase in ALP activity was observed during the 15 days of culture on both scaffold types and culture conditions (Fig. 3). For the SPCL fiber meshes, the ALP (normalized to reflect the ALP activity per cell) was not statistically different between flow perfusion and static cultures. However, the ALP activity in SEVA-C scaffolds cultured under flow conditions after 15 days was higher $(p<0.05)$ than ALP activity in static culture conditions for the same time period.

\section{Calcium deposition}

Calcium deposition in cultures of osteoblastic cells is a marker of their full maturation. Calcium measurements (Fig. 4) showed that during the first week of culture practically no calcium deposition had occurred in both culture conditions. In contrast, after 15 days, a dramatic increase in calcium deposition was observed on both types of scaffolds cultured under flow perfusion, clearly suggesting that flow perfusion is responsible for the enhanced mineralization of marrow stromal cells. Possible mechanisms responsible for the

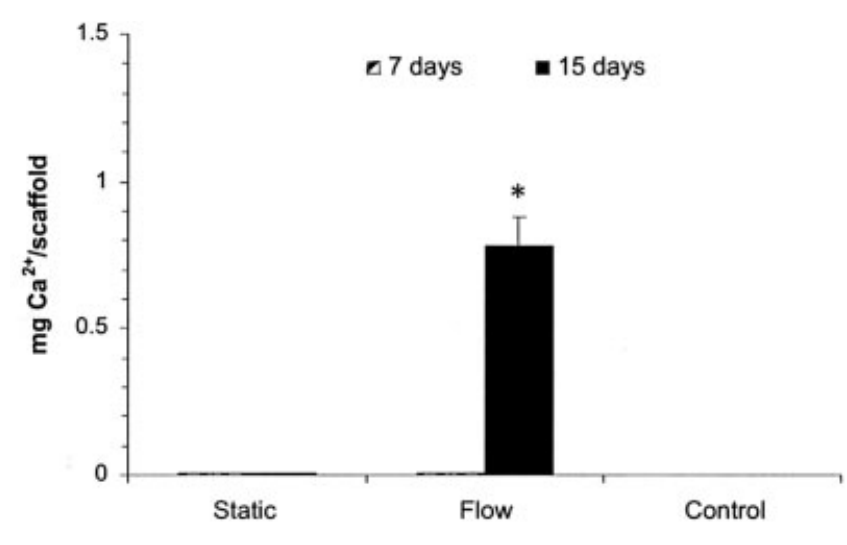

a)

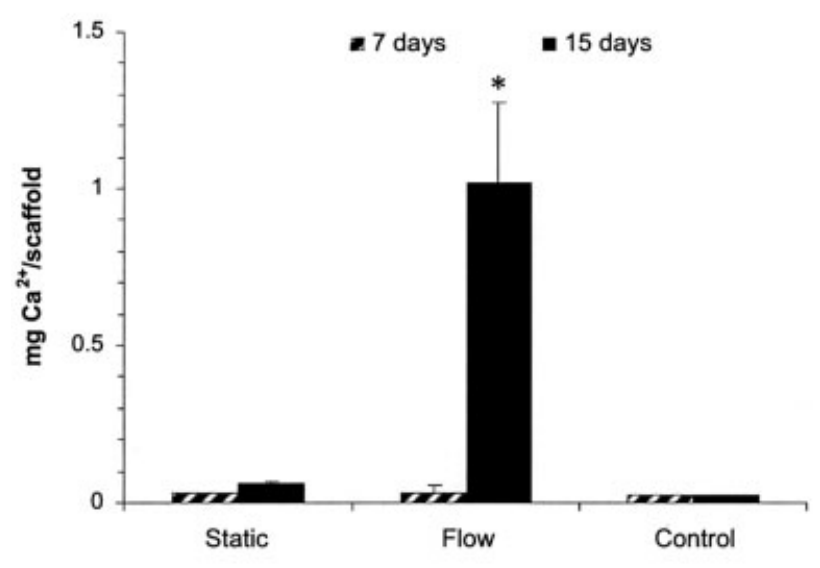

b)

Figure 4. Calcium deposition on (a) SPCL fiber meshes and (b) SEVA-C based scaffolds after 7 and 15 days of culture under static and flow perfusion conditions. Control samples without cells were also "cultured" under static conditions. Error bars, means \pm standard deviation for $n=3-5$. Asterisk $\left({ }^{*}\right)$ indicates that calcium deposited on the scaffolds cultured under flow perfusion conditions after 15 days of culture was significantly higher $(p<0.05)$ than calcium deposited on scaffolds cultured under static conditions for 15 days (and scaffolds cultured under flow perfusion conditions for 7 days). 

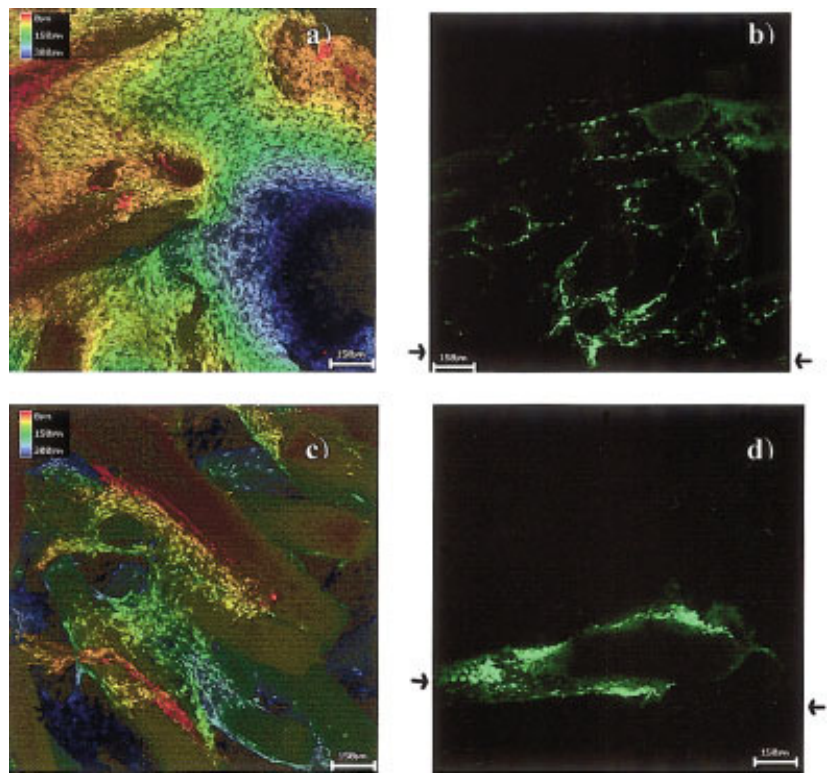

Figure 5. Confocal microscopy images of SPCL fiber meshes cultured for 15 days obtained from depth projections of the top surface (where cells were seeded) of samples cultured under (a) flow perfusion or (c) static conditions, and showing cell distribution along a transversal section from the surface (indicated by the arrow) to the interior of the scaffolds cultured under (b) flow perfusion or (d) static conditions. Bar is $150 \mu \mathrm{m}$.

observed enhanced mineralization include the exposure of the seeded cells to fluid shear induced mechanical stimulation and the mitigation of potential nutri-
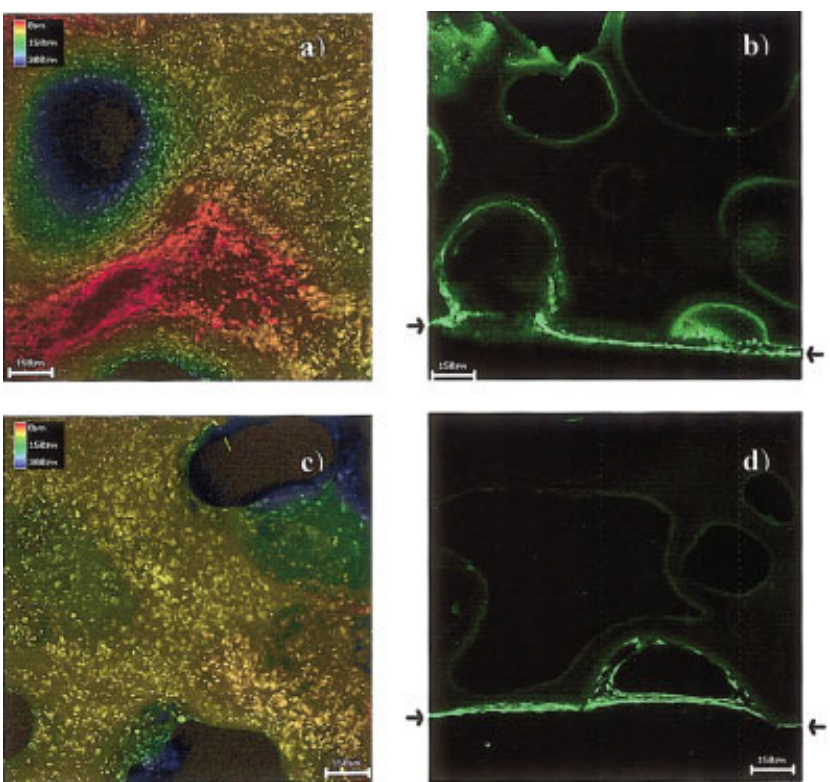

Figure 6. Confocal microscopy images of SEVA-C based scaffolds cultured for 15 days obtained from depth projections of the top surface (where cells were seeded) of samples cultured under (a) flow perfusion or (c) static conditions, and showing cell distribution along a transversal section from the surface (indicated by the arrow) to the interior of the scaffolds cultured under (b) flow perfusion or (d) static conditions. Bar is $150 \mu \mathrm{m}$.

ent transport limitations experienced by the cells cultured under static conditions.

Enhanced mineralization under flow perfusion
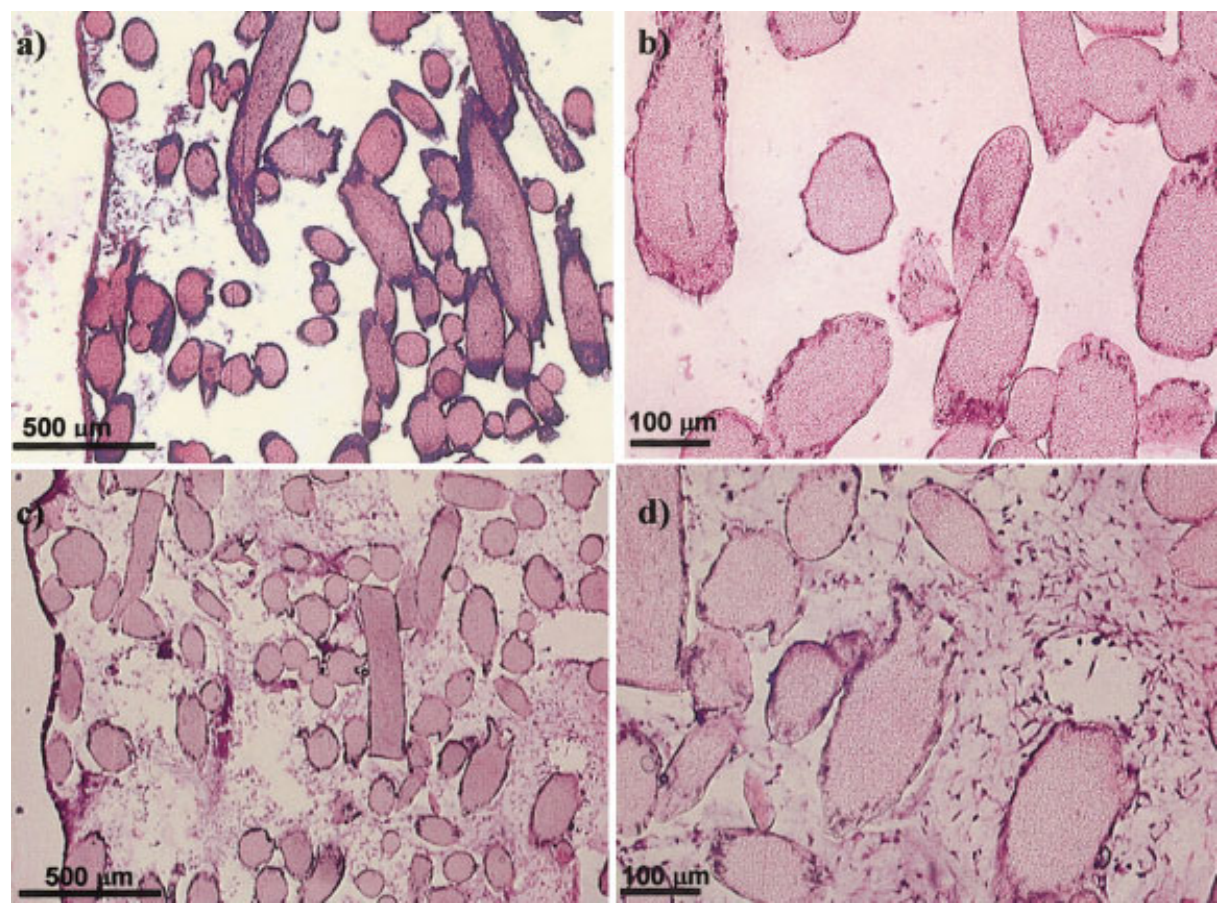

Figure 7. Histological sections of SPCL fiber meshes cultured for 15 days and stained with hematoxylin and eosin, at different magnifications, in static $(a, b)$ and flow perfusion culture $(c, d)$. 

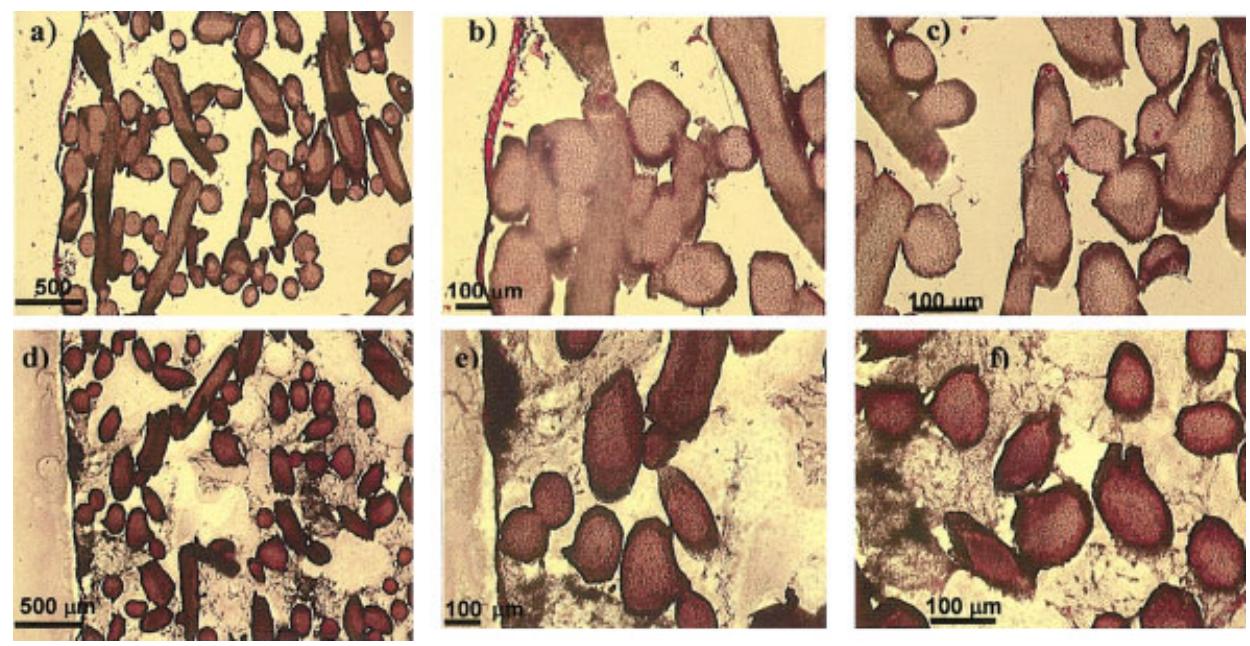

Figure 8. Von Kossa stained histological sections of SPCL fiber meshes cultured for 15 days, at different magnifications, under static $(\mathrm{a}-\mathrm{c})$ and flow perfusion conditions $(\mathrm{d}-\mathrm{f})$.

appeared in both scaffold types in agreement with earlier studies involving the culture of marrow stromal cells on titanium fiber meshes under flow perfusion with similar shear forces. ${ }^{26}$ From the porosity and pore size of the scaffolds, a mean shear stress could be estimated for fluid flow through the pores. ${ }^{25}$ Assuming a cylindrical pores model approximation for the geometry of the scaffold porosity, the shear forces experienced by the seeded cells in both scaffolds were estimated to be on the order of $0.1 \mathrm{dyn} / \mathrm{cm}^{2}$.

\section{Confocal microscopy}

Confocal images obtained from depth projections of the surfaces of SPCL fiber meshes after 15 days showed the formation of cell monolayers on the surface of the scaffolds cultured under flow [Fig. 5(a)] and static [Fig. 5(c)] conditions, but the images suggested the presence of a thicker layer of cells on samples cultured in the flow perfusion bioreactor. The images obtained from the transversal section of the same samples demonstrated that the flow culture conditions [Fig. 5(b)] allow for a much better distribution of cells inside the fiber meshes than the static culture conditions [Fig. 5(d)].

In the SEVA-C-based scaffolds, the formation of cell monolayers on the surface of the scaffolds cultured under flow [Fig. 6(a)] and static conditions [Fig. 6(c)] was apparent. However, the images obtained from the transversal section of the samples [Fig. 6(b,d)] demonstrated that, in this case, the limited pore connectivity of these scaffold did not allow the cells to spread throughout the scaffold interior. Nevertheless, in the samples cultured in the flow perfusion bioreactor, it was possible to visualize a small number of cells in the interior of the scaffold, indicating the existence of a preferential flow pathway through these scaffolds that allowed the presence of cells in specific locations.
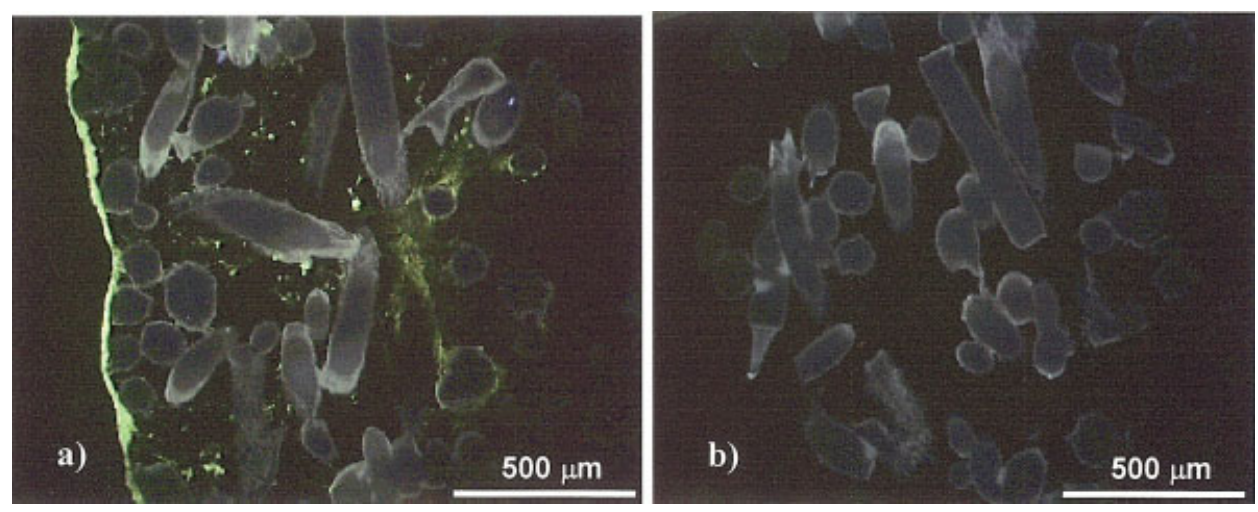

Figure 9. Sections of SPCL fiber meshes cultured for 15 days observed under fluorescent light, showing the tetracycline labelling of mineral in (a) flow perfusion and (b) static culture conditions. 

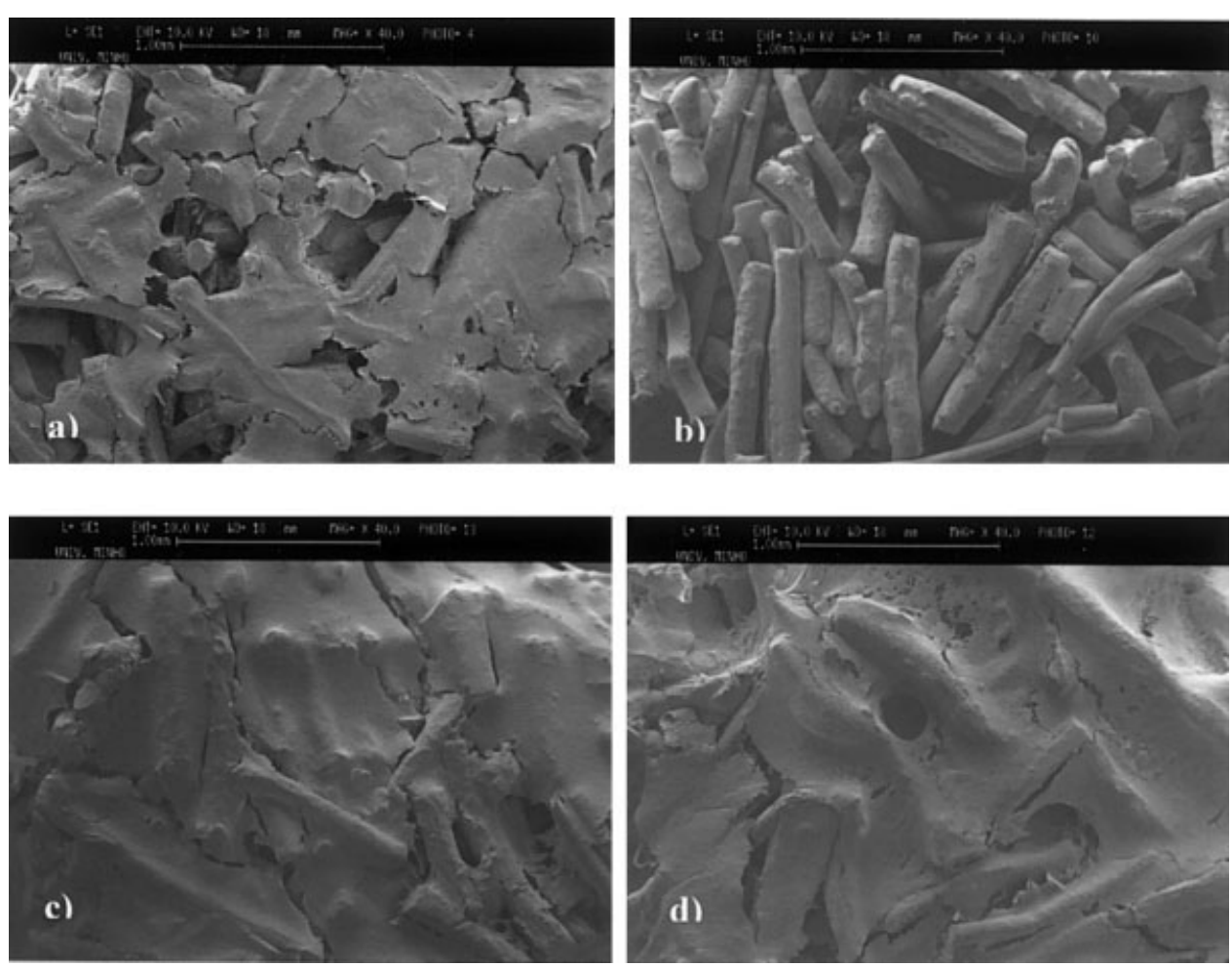

Figure 10. SEM micrographs depicting the surface of SPCL fiber meshes cultured for 15 days: (a,c) top surface (surface where cells were seeded), (b,d) bottom surface (opposite to the surface where cells were seeded) of samples cultured under static $(a, b)$ or flow perfusion conditions $(c, d)$. Bar is $1 \mathrm{~mm}$.

\section{Histological evaluation}

Hematoxylin and eosin staining

Histological sections of SPCL scaffolds after 15 days culture [Fig. 7(a,b)] demonstrated the formation of a cell layer on the surface of the cultured fiber meshes, but not in the interior, under static conditions. In contrast, the constructs cultured under flow conditions [Fig. 7(c,d)] exhibited a much better cell distribution. The histological analysis of SPCL scaffolds cultured for 15 days was in agreement with the conclusions drawn from confocal imaging. Once again, the presence of cells inside the scaffolds cultured under flow perfusion was observed, whereas scaffolds cultured under static conditions resulted only in a surface layer of cells (Fig. 7). These results confirm that flow perfusion culture enhances cell distribution in three-dimensional, starch-based scaffolds.

\section{Von Kossa staining}

Figure 8(a-c) shows no mineral deposition on scaffolds cultured under static conditions. However, Von Kossa stained sections revealed that the mineralized tissue was distributed throughout the scaffolds cultured under flow perfusion [Fig. 8(d-f)] in agreement with the histological observations and the calcium deposition measurements.
Tetracycline fluorescence

In Figure 9(a) the formation of a mineral layer on the surface of the scaffold is apparent. It is also possible to identify several regions in the interior of the scaffolds where mineral deposition has occurred. Once again, no mineral deposition is observed on the scaffolds cultured under static conditions [Fig. 9(b)]. These results, together with the analysis of Von Kossa staining and calcium deposition, suggest that flow perfusion culture enhances the osteogenic differentiation of marrow stromal cells and improves their distribution in three-dimensional, starch-based scaffolds by possibly improving nutrient delivery in the interior of the scaffolds or by stimulating the seeded cells by exposing them to fluid shear forces.

\section{Scanning electron microscopy}

Figure 10 shows SEM micrographs depicting the top (where the cells were seeded) and bottom surface of SPCL fiber meshes cultured for 15 days under flow and static conditions, respectively. The scaffolds cultured under flow perfusion conditions were completely covered by a dense matrix coating on both bottom and top surfaces, which suggests that cells were able to migrate throughout the scaffold and fill the entire construct. In contrast, the top surface of the 
scaffolds cultured under static conditions exhibited a thin crusting layer of extracellular matrix, and on the bottom surface it is only possible to observe the coating of some of the fibers. These observations reinforce the conclusion that flow perfusion enhances cell distribution in scaffolds cultured in vitro.

\section{CONCLUSIONS}

The two types of starch-based scaffolds selected for this study promoted the attachment and proliferation of rat bone marrow stromal cells. However, the SPCL fiber meshes showed increased cell proliferation because of the better interconnectivity of their porous structure. This study demonstrates the ability of the flow perfusion bioreactor to enhance the osteogenic differentiation and the homogeneous distribution of marrow stromal cells within starch-based polymer scaffolds. Accordingly, starch-based porous scaffolds seeded with mesenchymal stem cells and cultured under flow perfusion constitute a promising approach for the generation of osteoinductive bone tissue replacement constructs.

The authors acknowledge Dr. Francesco Degli-Innocenti from Novamont, Italy, for supplying the starch-based polymers and Jeremy Lemoine at Rice University for the $\mu \mathrm{CT}$ imaging work.

\section{References}

1. Freed LE, Vunjak-Novakovic G. Culture of organized cell communities. Adv Drug Deliv Rev 1998;33:15-30.

2. Thomson RC, Wake MC, Yaszemski MJ, Mikos AG. Biodegradable polymer scaffolds to regenerate organs. Adv Polym Sci 1995;122:247-274.

3. Langer R. Selected advances in drug delivery and tissue engineering. J Controlled Release 1999;62:7-11.

4. Lu L, Mikos AG. The importance of new processing techniques in tissue engineering. MRS Bull 1996;21:28-32.

5. Langer R, Vacanti JP. Tissue engineering. Science 1993;260: 920-925.

6. Chen G, Ushida T, Tateishi T. Hybrid biomaterials for tissue engineering: a preparative method for PLA or PLGA-collagen hybrid sponges. Adv Mater 2000;12:455-457.

7. Laurencin C, Ambrosio A, Borden M, Cooper J. Tissue engineering: orthopedic applications. Ann Rev Biomed Eng 1999;1:19-46.

8. Mooney D, Mikos AG. Growing new organs. Scientific American 1999;280:38-43.

9. Hutmacher DW, Teoh SH, Zein I, Renawake M, Lau S. Tissue engineering research: the engineer's role. Med Dev Tech 2000; 1:33-39.

10. Middleton JC, Tipton AJ. Synthetic biodegradable polymers as orthopaedic devices. Biomaterials 2000;21:2335-2346.

11. Vacanti CA, Bonassar LJ. An overview of tissue engineered bone. Clin Orthop Rel Res 1999;367S:375-381.
12. Kim BS, Mooney D. Development of biocompatible synthetic extracellular matrices for tissue engineering. TIB TECH 1998; 16:224-230.

13. Chapekar MS. Tissue engineering: challenges and opportunities. J Biomed Mater Res (Appl Biomater) 2000;53:617-620.

14. Thomson RC, Yaszemski MJ, Powers JM, Mikos AG. Fabrication of biodegradable scaffolds to engineer trabecular bone. J Biomater Sci Polym Edn 1995;7:23-38.

15. Hutmacher DW. Scaffolds in tissue engineering bone and cartilage. Biomaterials 2000;21:2529-2543.

16. Freed LE, Vunjak-Novakovic G, Biron R, Eagles D, Lesnoy D, Barlow S, Langer R. Biodegradable polymers scaffolds for tissue engineering. Bio/Technology 1994;12:689-693.

17. Gomes ME, Reis RL, Cunha AM. Alternative tissue engineering scaffolds based on starch: processing methodologies, morphology, degradation behaviour and mechanical properties. Mater Sci Eng C Biomimet Supramolec Syst 2002;20:19-26.

18. Gomes ME, Reis RL, Cunha AM, van Blitterswijk CA, Bruijn JD. Cytocompatibility and response of osteoblastic-like cells to starch-based polymers: effect of several additives and processing conditions. Biomaterials 2001;22:1911-1917.

19. Mendes SC, Bovell YP, Reis RL, Cunha AM, Bruijn JD, van Blitterswijk CA. Biocompatibility testing of novel of starchbased materials with potential application in orthopaedic surgery. Biomaterials 2001;22:2057-2064.

20. Marques AP, Reis RL, Hunt JA. In vitro evaluation of the biocompatibility of novel biodegradable starch-based polymeric and composite materials. Biomaterials 2002;23:1471-1478.

21. Bruder SP, Caplan AI. Bone regeneration through cellular engineering. In: Lanza RP, Langer R, Vacanti JP, editors. Principles of tissue engineering, 2nd ed. New York: Academic Press; 2000. p 683-696.

22. Freed LE, Vunjak-Novakovic G. Tissue engineering bioreactors. In: Lanza RP, Langer R, Vacanti JP, editors. Principles of tissue engineering, 2nd ed. New York: Academic Press; 2000. p 143-156.

23. Sikavitsas VI, Bancroft GN, Mikos AG. Formation of threedimensional cell/polymer constructs for bone tissue engineering in a spinner flask and a rotating wall vessel bioreactor. J Biomed Mater Res 2002;62:136-148.

24. Botchwey EA, Pollack SR, Levine EM, Laurencin CT. Bone tissue engineering in a rotating bioreactor using a microcarrier matrix system. J Biomed Mater Res 2001;55:242-253.

25. Goldstein AS, Juarez TM, Helmke CD, Gustin MC, Mikos AG Effect of convection on osteoblastic cell growth and function in biodegradable polymer foam scaffolds. Biomaterials 2001;22: 1279-1288.

26. Bancroft GN, Sikavitsas VI, van den Dolder J, Sheffield TL, Ambrose CG, Jansen JA, Mikos AG. Fluid flow increases mineralized matrix deposition in $3 \mathrm{D}$ perfusion culture of marrow stromal osteoblasts in a dose-dependent manner. Proc Natl Acad Sci USA 2002;99:12600-12605.

27. Begley CM, Kleis SJ. The fluid dynamic and shear environment in the NASA/JSC rotating-wall perfused-vessel bioreactor. Biotech Bioeng 2000;70:32-40.

28. Glowacki J, Mizuno S, Greenberger JS. Perfusion enhances functions of bone marrow stromal cells in three-dimensional culture. Cell Transplant 1998;7:319-326.

29. Maniatopoulos C, Sodek JM. Bone formation in vitro by stromal cells obtained from bone marrow of young adult rats. Cell Tissue Res 1988;254:317-330.

30. van den Dolder J, Bancroft GN, Sikavitsas VI, Spauwen PHM, Jansen JA, Mikos AG. Flow perfusion culture of marrow stromal osteoblasts in titanium fiber mesh. J Biomed Mater Res Part A 2003;64A:235-241.

31. Lian JB, Stein GS. Concepts of osteoblast growth and differentiation: basis for modulation of bone cell development and tissue formation. Crit Rev Oral Biol Med 1992;3:269-305. 